\title{
The role played by social-ecological resilience as a method of integration in interdisciplinary research
}

\author{
$\underline{\text { Simone A. Beichler }}^{1}$, Sanin Hasibovic $^{1}$, Bart Jan Davidse $^{1}$ and Sonja Deppisch $^{1}$
}

\begin{abstract}
Today's multifaceted environmental problems, including climate change, necessitate interdisciplinary research. It is however difficult to combine disciplines to study such complex phenomena. We analyzed the experience we gained in applying a particular method of interdisciplinary integration, the 'bridging concept.' We outlined the entire process of developing, utilizing, and adapting social-ecological resilience as a bridging concept in a research project involving seven different disciplines. We focused on the tensions and opportunities arising from interdisciplinary dialogue and the understandings and manifestations of resilience in the disciplines involved. By evaluating the specific cognitive and social functions of resilience as a method of integration, we call for placing greater emphasis on the quality and value of the actual interdisciplinary process, rather than concentrating solely on the output of interdisciplinary work.
\end{abstract}

Key Words: adaptation; bridging concept; climate change; interdisciplinarity; resilience

\section{INTRODUCTION}

Research on climate change impacts, effects, and adaptation options requires research approaches that not only combine social and biophysical factors but also their associated disciplines. To take the multifaceted characteristics of climate change into account, integrative research approaches are needed (Deppisch and Hasibovic 2013). Interdisciplinarity is not achieved by merely bringing different disciplines together in a joint research project; it rather represents itself as an intellectual challenge (Kinzig 2001). Thus, a structured approach is needed to prevent an interdisciplinary study from becoming, as Cornell and Parker (2010:31) put it, "a chaotic mix of social interpretation and physical facts."

We present a process of interdisciplinary integration, through the example of a research project on climate change and spatial development. The project takes a social-ecological approach and focuses on the development of adaptation strategies for urban regions. The researchers involved in the project come from different disciplines, ranging from natural to social sciences. The project itself comprises seven individual subprojects and a crosssectional project in which the individual results are integrated. To achieve a level of interdisciplinary integration, which constitutes more than just multidisciplinary discussions and the consolidation of results, resilience serves as a bridging concept.

The concept of resilience has gained a lot of attention in the literature (Holling 1996, Adger 2000, Folke 2006, Smit and Wandel 2006, Walker et al. 2006). The same is true for theoretical considerations on cross-disciplinary integration, by means of interdisciplinary, multidisciplinary, or transdisciplinary approaches (Lattuca 2003, Bracken and Oughton 2006, Buller 2009, Cornell and Parker 2010, Mobjörk 2010, Stock and Burton 2011). The process of integration itself has however received little attention so far. We intend to fill this gap by paying particular attention to the actual interdisciplinary process and the potential of resilience as an integration tool for projects on climate change adaptation. To do so, we discuss how the use of resilience as a bridging concept has been facilitating the interdisciplinary research process and we reflect on the degree of interdisciplinary integration we achieved in the project.

\section{METHODS AND CONCEPTUAL FRAMEWORK}

\section{The research project under consideration}

The research project under consideration investigates the topic of adaptation to climate change in the context of urban and regional development in urban regions at the Baltic Sea coast. As such, the case studies in all subprojects share a common geographical focus and take the city and its hinterland (urban region) into consideration. The key study areas are Stockholm (Sweden) and Rostock (Germany). The project ultimately aims to contribute to the development of climate change adaptation strategies. The seven subprojects and the cross-sectional project are represented in Figure 1. Within the research group, scientists with a background in earth system science, spatial planning, landscape ecology, geography, and communication sciences have been cooperating intensively for three years. To structure the process of interdisciplinary integration, different methods were applied: (1) common research questions; (2) a unified problem definition and problem-solving orientation; and (3) a common intellectual framework, the bridging concept. Despite the importance of the first two methodological steps, the latter is the key focus of this paper.

\section{The bridging concept}

Our objective was to develop a bridging concept that could act as a common conceptual point of reference to connect and integrate approaches, questions, and perspectives of the disciplines involved. The main functions of a bridging concept are cognitive and social, referring to assumptions underlying the theoretical concepts and methods and as a tool for cooperation and communication defining a common vocabulary, respectively (Becker 2012). We started the interdisciplinary process with the open concept of resilience because it has the potential for development in a recursive process within the research group.

${ }^{1}$ HafenCity University Hamburg 
Because we are interested in the role played by the bridging concept in the process of interdisciplinary integration, we used the cognitive and social function of the use of the bridging concept to structure the analysis.

Fig. 1. The interdisciplinary project structure.

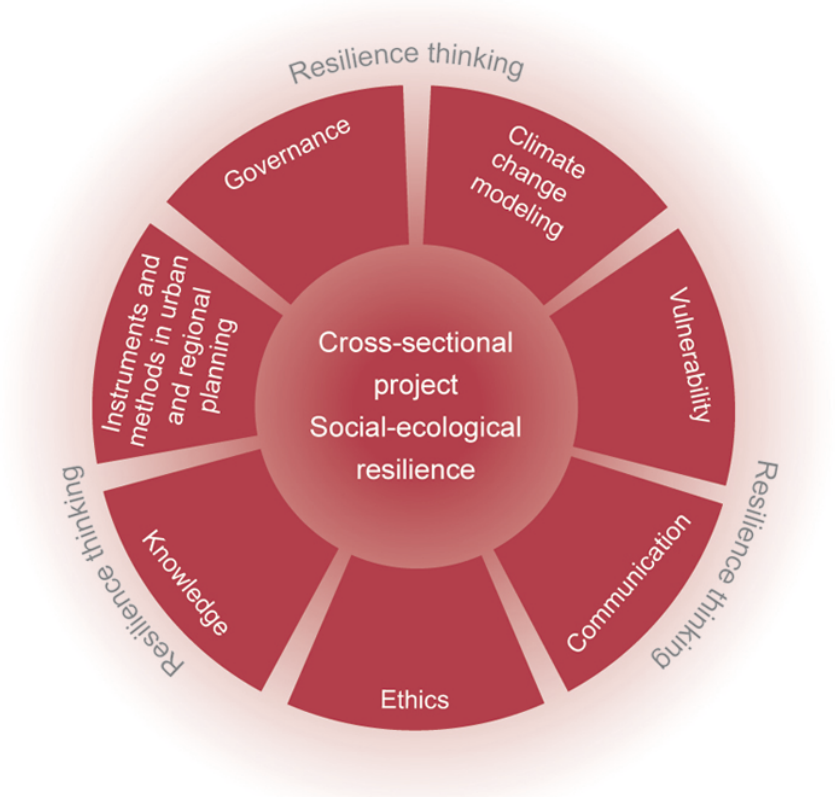

\section{Interdisciplinarity}

The literature contains various definitions of cross-disciplinary approaches, mostly with a widely acknowledged differentiation into the following categories: multidisciplinarity, interdisciplinarity, and transdisciplinarity (Barry et al. 2008, Mobjörk 2010, Stock and Burton 2011). The differentiation between those categories can be made based on the actors involved and the motives of integration from a 'synthesis phase' to a shared problem definition (Mobjörk 2010). Multidisciplinarity is the least integrative form, in which researchers from different disciplines coexist, summarizing different expert opinions, whereas in interdisciplinary approaches researchers deliberately cross disciplinary boundaries (Mobjörk 2010, Stock and Burton 2011). It needs to be noted that transdisciplinarity can be understood as both a cross-disciplinary category including practitioners outside academia (Mobjörk 2010) or as an "articulation between disciplines" (Ramadier 2004:424), we applied the latter understanding as a form of interdisciplinarity. Against this background, the project under consideration is interdisciplinary, as it includes several disciplines and engages in integrated research, through shared research questions and a cross-sectional project. However, there are a lot of taxonomies of interdisciplinary research approaches, with various grades of intensity (Barry et al. 2008, Buller 2009, Huutoniemi et al. 2010). Despite this richness in theory, the operationalization is difficult and multiple dimensions, i.e., empirical, methodological, and theoretical interdisciplinarity, need to be considered (Huutoniemi et al. 2010). To reflect upon the mode of interdisciplinarity achieved in our project, we will discuss those dimensions and apply the classification of Lattuca
(2003:6-7): (1) 'Informed disciplinarity' implies disciplinary research that sporadically reaches out to other fields in terms of concepts and methods; (2) 'Synthetic interdisciplinarity' comprises research based on questions that link disciplines and are at "the intersections of disciplines;" (3) 'Transdisciplinarity' comprises research questions and methods that cross and transcend disciplines; and (4) 'Conceptual interdisciplinarity' involves questions that have no "compelling disciplinary basis."

\section{The interdisciplinary dialogue}

During the research project, we have been in a continuous interdisciplinary dialogue aimed at the joint development of a resilience concept to integrate the perspectives and results of the subprojects. In this dialogue, we distinguished two parallel processes, the one comprising the development of the bridging concept itself and the other comprising the manifestation of the bridging concept within the subprojects. These two processes are visualized in Figure 2.

Fig. 2. The interdisciplinary dialogue.

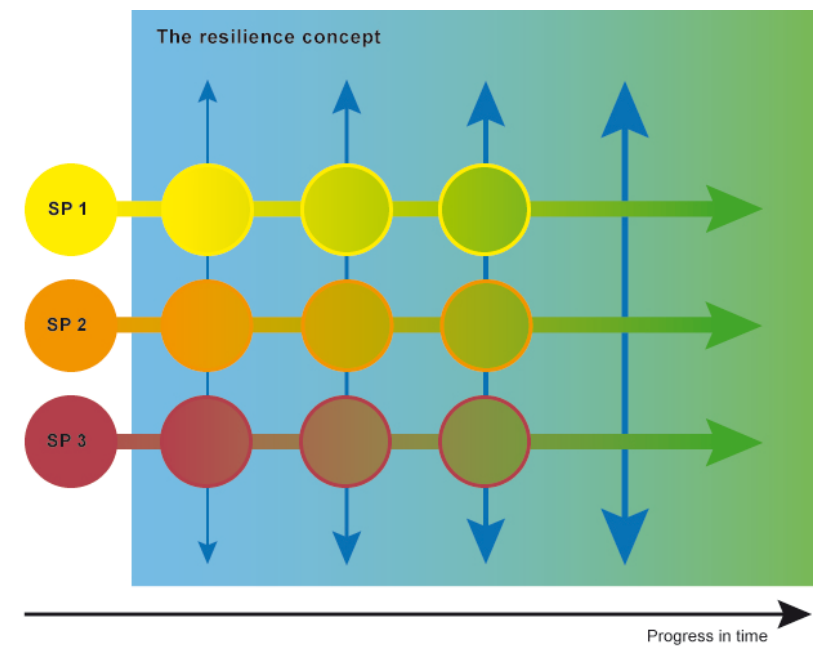

The blue to green background in Figure 2 represents the development of the bridging concept through time. The development of the bridging concept ran in parallel to the research processes in the individual subprojects (SP). These are represented by the circles in different colors to indicate the disciplinary orientation. Throughout the process, the bridging concept and the subprojects significantly influenced each other, leading to adjustments of the bridging concept as well as of the individual subprojects (changing colors and arrows in Fig. 2). For analytical purposes, we examined these two parallel processes separately.

\section{SOCIAL-ECOLOGICAL RESILIENCE AS THE BRIDGING CONCEPT}

\section{Developing the bridging concept}

The process of developing the bridging concept started with an extensive literature review on general principles of resilience and related concepts, such as vulnerability and adaptive capacity. As a result, our initial understanding of resilience was influenced by the work of authors such as: Carpenter et al. (2001), Gunderson and Holling (2002), Walker et al. (2004, 2006), Adger et al. (2005), 
Adger (2006), Folke (2006), Gallopín (2006), Smit and Wandel (2006), and Füssel (2007). Over the years, resilience research has become hugely productive and has strayed from the confines of its original discipline. Thus, it evolved into a very broad but multifaceted concept for the description of self-organized complex systems that change over time (Martin-Breen and Anderies 2011). In this heterogeneous field, we had to find an understanding of resilience that was suitable for the purpose of conceptually integrating disciplinary perspectives in our project.

After examining resilience concepts across a range of theoretical perspectives, we ruled out some notions of resilience, such as 'engineering resilience' (Holling 1996), in favor of a more strategic approach to resilience, encompassing the general idea of learning and evolving systems and living with change and disturbance. We also rejected concepts of resilience with strong disciplinary backgrounds, such as social resilience and ecological resilience (Adger 2000) because of the interdisciplinary nature of our research questions. As a result of the discussion process, we opted for social-ecological resilience (SER; Folke 2006). We considered SER to be suitable because the concept deals with global environmental change and has a systemic character. In combined social-ecological systems, the social and ecological systems cannot be approached separately because of the inherent feedbacks and interdependencies between the systems (MEA 2005). This systemic approach can facilitate the integration of natural and social sciences and bridge their conceptual approaches. Thus, we conceptualized urban regions as socialecological systems in each of the seven subprojects. Furthermore, SER offers a strategy for dealing with potential nescience, uncertainty, and surprise, mainly attributed to the hybrid phenomenon of climate change and related impacts (O'Brien et al. 2009). Hence, the concept of social-ecological resilience incorporates a flexible, integrative, epistemological approach for interdisciplinary research (Deppisch and Hasibovic 2013).

\section{Interdisciplinary dialogue on social-ecological resilience}

After the decision to use SER as bridging concept, we continued the interdisciplinary dialogue with a process to devise an integrative definition of SER that could connect with all of the disciplinary perspectives represented in our project. This process included the clarification of elements and the specification or rewording and extension of existing SER concepts. The formulation of a joint definition proved to be challenging and time consuming because of conceptual differences of disciplines, as well as the specific research questions in the subprojects. After prolonged debate, we were able to draw up the following working definition of SER, based on the lowest common conceptual denominator:

"Social-ecological resilience is the capacity of an urban region to absorb uncertain climatic stimuli and their effects so as to maintain the essential social and ecological functional and structural properties while undergoing change."

The basic common elements of this understanding of SER can be summed up by three major issues: (1) resilience as a capacity (Walker et al. 2004); (2) a contextualized notion of resilience, i.e., resilience of what to what (Carpenter et al. 2001); and (3) change and complexity as being intrinsic to social-ecological systems (Adger et al. 2005, Folke 2006). Given the context of our project, exploring adaptation to climate change in urban regions, we consider SER to be more than a system's ability to maintain structure and function in the face of disturbance. It is the system's ability to adapt, learn, and allow for continuous development under climate change. These principles have been largely accepted in the resilience literature. Notwithstanding, we encountered problems including them in a joint definition, mostly not because of the principles themselves, but because of their different meanings among disciplines. This applied to several issues, such as considerations of scale, the political/power dimension of resilience, the degree of self-organization in complex systems, sense-making and interpretative/symbolic dimensions of SER, the ability to achieve transformative change, and the degree of normativity entailed in the SER concept. Several of these contested issues have been discussed in the literature, especially the matters of power, politics, and social construction of a system's boundaries (Hornborg 2009, Evans 2011, Davoudi 2012). Within our interdisciplinary dialogue we addressed all these issues in depth, facilitating a clarification and to some extent convergence of perspectives. However, some contested issues remained. Thus, the working definition as outlined above was unable to be fully adopted by all of the participating disciplines.

Faced with this problem, we shifted our focus from the conceptual precision to the conceptual vagueness of the SER concept. The reasons behind this decision related to an important step in interdisciplinary work, the identification and acknowledgement of the variety of meanings and of possible structures (Strunz 2012). As such, the search for an integrated definition of resilience enabled us to reveal, discuss, and productively use the different theoretical positions represented in the research group. This was a very time-consuming process, not only discussing the different disciplinary notions of SER, but the underlying assumptions and the ontological and epistemological fundamentals of disciplinary perspectives on resilience.

In search for a set of more general principles of SER we turned to SER thinking (Folke et al. 2010), emphasizing the socialecological context, including principles such as complexity, transformational change, uncertainty, surprise, and potential nescience. By using these principles instead of a strict definition, all subprojects could agree on the concept of SER thinking as an endpoint, meaning that SER thinking set the basis or a normative setting for discussing adaptation measures. Consequently, the conceptual vagueness proved to be an asset in our interdisciplinary research context because it facilitated crossdisciplinary communication and contributed to pragmatic solutions in terms of an interdisciplinary development of adaptation strategies inspired by SER thinking, as observed by Strunz in other contexts (2012).

The shift from trying to develop a common definition of SER to the use of social-ecological resilience thinking is the most prominent example of the way in which the work within the individual subprojects influenced the bridging concept. One reason being, a precise definition of the factors determining resilience, such as adaptive capacity was a crucial factor to some subprojects that would require a consistent application of the approach.

\section{Manifestation of resilience within the subprojects}

Each discipline contributed to the debate on SER and at the same time incorporated conceptual impulses into their subprojects, 
sometimes leading to modifications of research questions, methods, or epistemological perspectives. The outcome of operationalizing the general principles of resilience across the different fields of research was as follows:

In the 'climate change modeling' subproject, uncertainty played a crucial role as a major aspect of resilience. On the one hand, there were uncertainties about the future development of climate change, including different scenarios, as well as uncertainties intrinsic to the models because of inadequately understood effects in the climatic system and the future development of greenhouse gas emissions. On the other hand, urban spatial development and its feedback to local climates are underexplored. Moreover, clearly defined spatial and temporal scales constituted an important basis of analysis.

In the theoretical framework of the 'vulnerability' subproject, resilience was seen as an overall system property influencing system behavior in case of change. The vulnerability was embedded as one characteristic of the social-ecological system influencing resilience, explicitly not antonymic to resilience. The key factors of vulnerability are exposure, sensitivity, and adaptive capacity. Adaptive capacity was thereby seen as an inherent property of the overall system, influencing both the overall vulnerability and resilience. Moreover, the goal of the subproject was to develop long term, sustainable adaptation measures based on the analysis of the system, driven by the normative setting of resilience thinking.

In the subproject concerning 'instruments and methods in urban and regional planning,' the resilience concept was not explicitly used. It was inspired however, by the more open notion of resilience thinking because approaches in planning theory show parallels to the resilience concept. Aspects such as nonlinearity, uncertainty, self-organization, learning processes, and adaptive capacity were taken into account (Fürst 2008, Hillier 2008). In addition, dealing with unpredictable and nonmanageable developments (Frey et al. 2008) played an important role. Against the background of the complexity and dynamics of future developments, planning theory approaches called for flexibility and adaptability in planning practice (Fürst 2008, Wiechmann 2008). There was also ongoing debate about resilience in the context of spatial planning. However, the lack of operationalization hampered its implementation in planning practice (Overbeck et al. 2008).

In the 'governance' subproject, resilience and the closely related concept of adaptive capacity helped shape the subproject's context and its position within the project as a whole, although the actual focus was on multilevel governance structures. In this regard, this subproject endorsed the normative assumption that multilevel governance structures can positively influence adaptive capacity, enhancing the resilience of a social-ecological system, which could make a more sustainable contribution to adaptation to climate change (Folke et al. 2005, Armitage and Plummer 2010). The added value of the resilience perspective in this subproject was considered to be the opportunity to assess governance structures as part of the social-ecological system, such that the actions of stakeholders and the relations between them influenced the state of the system.

The 'knowledge' subproject entailed the concept of SER that highlights change and social learning. Departing from the definitions of SER put forward by Walker et al. (2004) and Folke (2006), this subproject assumed that a social-ecological system could adapt and change only through learning, i.e., by generating and exchanging knowledge, which constituted the basis for preserving and developing the social-ecological system. In this context, special attention is paid to double-loop learning processes, which are considered to be more important in changing and adapting a system than more frequent, simpler single-loop processes. In essence, knowledge generation and social learning contribute to building adaptive capacity.

In the 'communication' subproject, resilience was thought to constitute a specific form of a metadiscourse on climate change adaptation. The framing of climate change adaption along the lines of resilience thinking necessarily leads to a different nature and perception of adaptation. In this subproject, the resilience concept was largely influenced by notions of change, complexity, social construction, and power. Seen from this perspective, the subproject embraced the notion of evolutionary resilience, highlighting transformative change as an essential element of (evolutionary) resilience in social-ecological systems dealing with climate change (Davoudi 2012).

The 'ethics' subproject used a resilience concept that emphasized complexity and learning to live with change, adopting a perspective of social and ecological interdependencies, questioning previous paths taken, and considering potential transformation. This understanding of the term SER in the given context of climate change is not identical to the main definitions used in SER thinking because it adds the notion of further advancing or even transforming essential functional and structural properties. This widened resilience thinking approach is considered useful for tackling the challenges that the impact of future climate change places on current land-use decisions within planning. This is not only seen with respect to urban regions as human-dominated social-ecological systems, but also with reference to spatial planning as a deliberative act.

This overview indicates how the content of the individual subprojects was influenced by the bridging concept and it sheds light on the contested issues, such as differences in concepts of social-ecological systems and consequent essential structural and functional properties, the matter of temporal and spatial scales, tension between change and persistence, and the different notions of adaptive capacity, knowledge, and uncertainties.

\section{THE ADDED VALUE OF THE INTERDISCIPLINARY PROCESS}

\section{Cognitive functions}

The main cognitive function of using the bridging concept was the better understanding of the single elements of the resilience concept across disciplines. The complex problem of defining the social-ecological system was based on the initial definition of 'urban region.' This definition was crucial for the subprojects climate change modeling and vulnerability in terms of the spatial scale of assessment. In contrast, the subprojects planning instruments and governance were concerned with administrative scales that often differed from ecological processes in the landscape. Thus, the discussion of this specific element of the resilience definition contributed considerably to identifying demands regarding the issue of scale. We found that this demand differed, e.g., the extent of the study area for the spatial analysis 
was restricted to the city area plus hinterland because of data availability, whereas the area covered by the regional plan spanned a much wider area. Given the sole discussion on this element of resilience, different perspectives were uncovered that might otherwise have gone undetected. Different understandings of spatial- and temporal scale can lead to considerable interdisciplinary misunderstandings caused by the use of the same terms despite having a different understanding of these terms (Bracken and Ougthon 2006). Moreover, we found that the demand was shared to some extent. For example, the administrative scale of the city plan matched the spatial scale of analysis. Additionally, the discussion on the different meanings of 'land use' and 'land cover' categories in practical terms (planning and natural disciplines) lead to a shared definition and use of data, which is essential for the integration of results.

The resilience dialogue encouraged cooperation between disciplines. Opposing or contradictory perspectives enabled individual results to be reflected in this new context. To exemplify, the dialogue on different dimensions and scales of adaptive capacity led to a joint study between the vulnerability and governance subprojects, analyzing the interface of governance, vulnerability, and landscape ecology, untangling the problem of fit in social-ecological systems (S. A. Beichler, B. J. Davidse, and $\mathrm{S}$. Deppisch, unpublished manuscript). Another joint study dealt with recurring problems with mapping of adaptive capacity in vulnerability assessments, which were resolved by rethinking the indicators based on the concepts of knowledge exchange and generation in the context of climate change research (HagemeierKlose et al. 2014; S. A. Beichler, M. Hagemeier-Klose, and S. Deppisch, unpublished manuscript). In addition, the individual results of climate change modeling methodology were combined with planning theory involving planning tools (M. Richter, M. Albers, and S. Deppisch, unpublished manuscript). Such cooperation would have been impossible without the intense discussion on scales and related uncertainties.

The process of specifying and refining SER as the bridging concept led to new perspectives on the subprojects' research questions triggered by the expansion of the knowledge base, thus enhancing their results. For example, the differentiation of discursive and nondiscursive elements (realist ontology constructivist epistemology) was adapted in the communication subproject, and perception led to a new discourse theory that included not only social but also biophysical factors as being context-relevant. In the governance project, adaptive capacity became the essence of the conceptualization. The orientation of the subproject toward the study of multilevel governance structures was highly influenced by the debates on the connection between governance and adaptive capacity in the resilience literature. Moreover, the importance of knowledge and its dynamic nature, not only for adaptation but also for the measurement of adaptive capacity, was incorporated in the vulnerability subproject. As such, some subprojects experienced a remarkable degree of convergence on some issues, narrowing the gap to other disciplines.

A number of issues remained, giving rise to fruitful discussions. For example, there was intense debate on the wording of "to maintain ... while undergoing change." Here, we identified essential differences between the individual subprojects and disciplines that were more or less nonnegotiable because they concerned the conceptual core of the disciplines involved. From the natural science perspective, systems continuously adapt to environmental conditions, changing over the long term. Viewing the same issue from the planning perspective, the long-term perspective has a different meaning; it can only be accessed through the time span of the plans. Here again, the problem of differing definitions of social-ecological systems, including differing temporal scales, led to questions such as what should be maintained and what should be changed. This touched upon hot issues with regard to essential functions and properties of the system in question. Because of the individual structure and related methods of the subprojects, this needed to be addressed differently. This challenge is common to climate change projects because it is a constant struggle to define what the study's object is, the subsystems that are interacting, or the interactions themselves (Cornell and Parker 2010).

Reflecting on the cognitive function, a certain convergence of ontological views was achieved in the course of interdisciplinary dialogue. We found it very useful to utilize elements of the SER definition and to approach these elements from various disciplines. This enabled an interactive process through the construction of objects that "constitute the building blocks of interdisciplinarity" (Buller 2009:395). We deliberately exploited these single elements in detail to conceptualize the bridges between our subprojects. This not only resulted in a mutual understanding of concepts and methods, but also in an adaptation of the subprojects. The function of the bridging concept was most clearly expressed through the joint studies, bridging the disciplines of several subprojects, which go beyond the cross-sectional project. These joint studies were fuelled by SER as a tool for cooperation and communication, unravelling not only the cognitive function but also the social function of the bridging concept, as further elaborated on in the next section.

\section{Social functions}

The social function of SER was expressed in the interdisciplinary dialogue as well as in the cooperation between different team members. The social function was fuelled by characteristics of SER because it has a wide range of what we call 'docking points. ' It has a bridging character between disciplines in the field of climate change because in each of these disciplines, elements of the concept can be used when developing epistemic objects. Because of this accessibility, all of the disciplines in our research group were able to explore the basic assumptions of the other disciplines. This was achieved by asking provocative questions from their own disciplinary background phrased in SER vocabulary. For example, what is meant by 'capacity?' For climate change modeling, this could be narrowed down to the capacity of the soils in the urban region to absorb water and therewith 'absorb' events of heavy rain. From the governance perspective, 'capacity' relates directly to the term adaptive capacity, whereas for the vulnerability subproject the truth lies in between. This process not only reduced the space for disciplinary ignorance (Mengis et al. 2008), but also triggered an exploration of the other disciplines. As such, we were able to identify bridges and boundaries between the disciplines involved. This was particularly because of the focus on the complexity, multiple interactions, and feedbacks between social and biophysical elements in socialecological systems, which is the heart of SER. The notion of a complex, coupled human-nature system with emergent properties was quite challenging for all disciplines: for instance, the 
recognition by natural scientists of locally distinct, place-based, highly contextualized knowledge and its contingent nature or the acknowledgment by social scientists of material and energy flows that influence human society.

To enable our interdisciplinary work in the first place, we had to invest a considerable amount of time to develop a common vocabulary and find a common language. This went beyond the SER elements because it included dealing with disciplinary nomenclature or dialects (Bracken and Oughton 2006), with examples ranging from spatial heterogeneity to social construction. Moreover, the differences in methodological constructions of a research project from the pure strict experimental design and definition of variables of natural scientists, to the iterative process of interview design and discourse analysis. Here, the differences in the methods seem straightforward, but it required a process of interdisciplinary communication to grasp the entirely different nature of approaching a research question or problem, which is also evidenced by a different writing style (Bracken and Oughton 2006). Not only is this articulation difficult for conceptual reasons, but also for personal ones because researchers are by nature "systematically skeptical" (Ramadier 2004).

Through the process, we gained an understanding of each other's disciplinary background by continually articulating, questioning, clarifying, framing, and reframing our own and our common viewpoints. The search for a suitable interdisciplinary concept of SER provoked all of these rather fundamental questions that often go unchallenged within conventional disciplinary constraints. Social-ecological resilience displayed a strong social function as a bridging concept, stimulating cross-disciplinary communication and cooperation within our research group. In doing so, it also indirectly encouraged interdisciplinary integration because the strong social function fostered an in-depth understanding of the aims and finally the results of all subprojects, which in turn enabled us to reflect and combine these in an integrated manner.

\section{Discussing the mode of interdisciplinarity achieved}

We demonstrated how the use of SER as a bridging concept led to the fulfillment of a wide range of cognitive and social functions for the interdisciplinary integration in our research project. The mode of interdisciplinarity we achieved can best be described as closer to synthetic interdisciplinarity rather than transdisciplinarity (Lattuca 2003). Concerning the former, we were clearly able to identify and deal with questions at the intersection of all disciplines, for example, issues of scale and definition of an urban region. Achieving transdisciplinarity would have included research questions that crossed disciplines and that could only be answered by combining a variety of disciplines (Lattuca 2003). To some extent this was achieved with the joint studies on adaptive capacity, in which aspects of vulnerability and social learning were combined in a new theoretical concept, the 'dynamic knowledge loop' (Hagemeier-Klose et al. 2014). This study does not integrate the results of the overall project. To reach transdisciplinarity, we would have needed a joint definition of SER to subsume all disciplinary contributions under a larger theory. However, the contributions from individual disciplines have to be identifiable because we required distinct inputs from each field to obtain a comprehensive picture of our research objectives. As also observed by Cornell and Parker (2010), dealing with complex systems under climate change is not essentially a matter of aggregating disciplines but the topic needs to be broken down into manageable areas. As such, in our project the social-ecological system and its essential structures and functions were considered differently from various angles, taking, for example, institutions, land-use structure, or population density as research variables. In addition to this content-related reason, there was also a structural reason, the necessity to complete academic qualifications, which are inevitably discipline based. Nonetheless, because of the strong cognitive function of the bridging concept, the subprojects were adapted to a certain extent and as such reached a mode of informed disciplinarity themselves. This proves that the process of articulation was successful because through the creation of context and coherence disciplinary thinking changed (Ramadier 2004).

Our interdisciplinary dialogue confirmed how deeply entrenched the disciplinary notions of resilience are. These notions can, in theoretical terms, be retrieved from the study of Brand and Jax (2007), but in practical terms, the individual education and ideological boundaries of participating researchers also played a crucial role in the process. A descriptive resilience concept needs to be specific and build a basis for operationalization, but there can be trade-offs between social and ecological objectives (Brand and Jax 2007). As described in the section on the social functions, we not only experienced that the objectives differed, but also the way researchers of different disciplines operationalized. However, we took the first step to achieve transdisciplinarity or even conceptual interdisciplinarity by identifying those differences and trade-offs, such as, the boundaries of a system, issues of scale, the different understandings of change, and the diverging viewpoints on normativity and power.

At the end of our process, being unable to construct a joint SER definition, we shifted our focus to SER thinking. Looking at the sole outcome of the interdisciplinary process, this conceptual vagueness was an asset because it was a pragmatic solution everyone could agree on. One could argue that we could have saved time and resources by starting directly with this approach. However, acknowledging that general principles like uncertainty and complexity are inherent to all subprojects, the interdisciplinary mode achieved, could, in our opinion, only have been between informed disciplinarity and synthetic interdisciplinarity. Consequently, looking back at the interdisciplinary process, if we had come to conceptual precision, all provocative questions that needed to be answered gave space for fruitful discussions and resulting cognitive and social functions. Thus, contradictory to the standpoint of Brand and Jax (2007), we propose that the desired conceptual precision of an SER definition was more valuable to the interdisciplinary process than the vagueness of SER thinking. This is, however, a retrospective interpretation that is not generally applicable because interdisciplinarity is a "creative and iterative process that is, by nature, explorative rather than definite" (Buller 2009:402).

The interdisciplinary work in our example reached the point between synthetic interdisciplinarity and in part transdisciplinarity, acknowledging differences between disciplines, their individual strengths and contributions, and areas of contestation. Such a process was challenging and time consuming but built a strong research basis (Bracken and Oughton 2006), thus it facilitated giving integrated answers to our main research questions by 
obtaining a more comprehensive picture of adaptation to climate change in complex social-ecological systems. Seen from this perspective, the main purpose of the bridging concept, i.e., the facilitation of cross-disciplinary exchange and the process of converging different perspectives, was achieved.

\section{CONCLUSIONS}

The most important lesson that can be gained from our experience in using the resilience concept in our interdisciplinary work is the significance of the actual process. The initial objective was to find an interdisciplinary definition of resilience suitable for all of the subprojects of our project. Even though this objective proved to be unattainable, the actual process facilitated integration between participating disciplines by encouraging them to explore their own ontological and epistemological fundamentals. In this way, it became possible to discuss the opportunities of finding common ground at this more abstract level of interdisciplinary integration. Many 'hot issues' entailed in concepts of resilience, such as change and stability, scales, agency and power, decisively stimulated the discussion of our own views on these fundamental matters, providing corridors for understanding and conceptual convergence. The openness of the resilience concept and especially the immanent interdisciplinary nature of SER with a certain appeal to social, natural, and planning sciences, proved to be a valuable bridging concept. Every element in our SER definition provoked an intensive exchange between disciplines. Thus, SER as a bridging concept contributed to the initiation and facilitation of an interdisciplinary dialogue in our research group that not only embraced issues relevant to all disciplines, but also highlighted the bridges and boundaries between them.

We are convinced that SER is suitable for use as an integration tool in interdisciplinary projects dealing with climate change adaptation. The richness of the concept and its accessibility from a wide range of disciplines is simultaneously its Achilles heel. Although we were not able to achieve an integrated definition, based on cognitive and social functions, we support the proposition that the work toward a definition of SER was more valuable than the definition itself. The process helped us to achieve a significant convergence on several issues. The time and resources invested in the process are essential for building sustainable interdisciplinary bonds. We therefore advocate a greater focus on the quality and value of working interdisciplinarily, instead of concentrating merely on the output of interdisciplinary work.

Responses to this article can be read online at: http://www.ecologyandsociety.org/issues/responses. $\mathrm{php} / 6583$

\section{Acknowledgments:}

The authors thank all members of the research group plan B: Altic and Kaitlyn Rathwell for participation and contributions in the interdisciplinary process. Special thanks go to Maria HagemeierKlose for valuable comments to the manuscript and Meike Othengrafen for designing Figure 1. Furthermore, we thank all participants of the international workshop on the interdisciplinary understanding of resilience for their fruitful discussions. The research was funded by HafenCity University Hamburg and the
German Federal Ministry of Research and Education via the SocialEcological Research Programme (FKZ 01 UU0909).

\section{LITERATURE CITED}

Adger, W. N. 2000. Social and ecological resilience: are they related? Progress in Human Geography 24(3):347-364. http://dx. doi.org/10.1191/030913200701540465

Adger, W. N. 2006. Vulnerability. Global Environmental Change 16(3):268-281. http://dx.doi.org/10.1016/j.gloenvcha.2006.02.006

Adger, W. N., T. P. Hughes, C. Folke, S. R. Carpenter, and J. Rockström. 2005. Social-ecological resilience to coastal disasters. Science 309:1036-1039. http://dx.doi.org/10.1126/science.1112122

Armitage, D., and R. Plummer, editors. 2010. Adaptive capacity and environmental governance. Springer-Verlag, Berlin Heidelberg, Germany. http://dx.doi.org/10.1007/978-3-642-12194-4

Barry A., G. Born, and G. Weszkalnys. 2008. Logics of interdisciplinarity. Economy and Society 37(1):20-49. http://dx. doi.org/10.1080/03085140701760841

Becker, E. 2012. Social-ecological systems as epistemic objects. Pages 37-60 in M. Glaser, K. Gesche, B. Ratter, and M. Welp, editors. Human-nature interactions in the Anthropocene: potentials of social-ecological systems analysis. Routledge, London, UK.

Bracken, L. J., and E. A. Oughton. 2006. 'What do you mean?' The importance of language in developing interdisciplinary research. Transactions of the Institute of British Geographers 31:371-382. http://dx.doi.org/10.1111/j.1475-5661.2006.00218.x

Brand, F. S., and K. Jax. 2007. Focusing the meaning(s) of resilience: resilience as a descriptive concept and a boundary object. Ecology and Society 12(1): 23. [online] URL: http://www. ecologyandsociety.org/vol12/iss1/art23/

Buller, H. 2009. The lively process of interdisciplinarity. Area 41:395-403. http://dx.doi.org/10.1111/j.1475-4762.2008.00856.x

Carpenter, S. R., B. H. Walker, J. M. Anderies, and N. Abel. 2001. From metaphor to measurement: resilience of what to what? Ecosystems 4:765-781. http://dx.doi.org/10.1007/s10021-001-0045-9

Cornell, S., and J. Parker. 2010. Critical realist interdisciplinarity: a research agenda to support action on global warming. Pages 25-34 in R. Bhaskar, C. Frank, K. G. Høyer, P. Næss, and J. Parker, editors. Interdisciplinarity and climate change. Transforming knowledge and practice for our global future. Routledge, London, $\mathrm{UK}$.

Davoudi, S. 2012. Resilience: a bridging concept or a dead end? Planning Theory and Practice 13(2):299-307. http://dx.doi. org/10.1080/14649357.2012.677124

Deppisch, S., and S. Hasibovic. 2013. Social-ecological resilience thinking as a bridging concept in transdisciplinary research on climate-change adaptation. Natural Hazards 67(1):117-127. http://dx.doi.org/10.1007/s11069-011-9821-9

Evans, J. P. 2011. Resilience, ecology and adaptation in the experimental city. Transactions of the Institute of British Geographers 36:223-337. http://dx.doi.org/10.1111/j.1475-5661.2010.00420. $\underline{\mathrm{x}}$ 
Folke, C. 2006. Resilience: the emergence of a perspective for social-ecological system analyses. Global Environmental Change 16(3):253-267. http://dx.doi.org/10.1016/j.gloenvcha.2006.04.002

Folke, C., S. R. Carpenter, B. Walker, M. Scheffer, T. Chapin, and J. Rockström. 2010. Resilience thinking: integrating resilience, adaptability, and transformability. Ecology and Society 15(4): 20. [online] URL: http://www.ecologyandsociety.org/vol15/iss4/ $\underline{\operatorname{art} 20 /}$

Folke, C., T. Hahn, P. Olsson, and J. Norberg. 2005. Adaptive governance of social-ecological systems. Annual Review of Environment and Resources 30:441-473. http://dx.doi.org/10.1146/ annurev.energy.30.050504.144511

Frey, O., A. Hamedinger, and J. S. Dangschat. 2008. Strategieorientierte planung im kooperativen taat - eine einführung. VS Verlag für Sozialwissenschaften, Wiesbaden, Germany.

Fürst, D. 2008. Begriffe der planung und entwicklung der planung in Deutschland. Pages 21-47 in D. Fürst and F. Scholles, editors. Handbuch theorien und methoden der raum- und umweltplanung. Verlag Dorothea Rohn, Dortmund, Germany.

Füssel, H.-M. 2007. Vulnerability: a generally applicable conceptual framework for climate change research. Global Environmental Change 17:155-167. http://dx.doi.org/10.1016/j. gloenvcha.2006.05.002

Gallopín, G. C. 2006. Linkages between vulnerability, resilience, and adaptive capacity. Global Environmental Change 16:293-303. http://dx.doi.org/10.1016/j.gloenvcha.2006.02.004

Gunderson, L. H., and C. S. Holling, editors. 2002. Panarchy: understanding transformations in human and natural systems. Island, Washington, D.C., USA.

Hagemeier-Klose, M., S. A. Beichler, B. J. Davidse, and S. Deppisch. 2014. The dynamic knowledge loop: inter- and transdisciplinary cooperation and adaptation of climate change knowledge. International Journal of Disaster Risk Science 5:21-32. http://dx.doi.org/10.1007/s13753-014-0015-4

Hillier, J. 2008. Plan(e) speaking: a multiplanar theory of spatial planning. Planning Theory 7(1):24-50. http://dx.doi. org/10.1177/1473095207085664

Holling, C. S. 1996. Engineering resilience versus ecological resilience. Pages 31-44 in P.C. Schulze, editor. Engineering within ecological constraints. National Academy, Washington, D.C., USA. [online] URL: http://www.environmentalmanager.org/wpcontent/uploads/2008/03/holling-eng-vs-eco-resilience.pdf

Hornborg, A. 2009. Zero-sum world: challenges in conceptualizing environmental load displacement and ecologically unequal exchange in the world-system. International Journal of Comparative Sociology 50(3-4):237-262. http://dx.doi. org/10.1177/0020715209105141

Huutoniemi, K., J. T. Klein, H. Bruun, and J. Hukkinen. 2010. Analyzing interdisciplinarity: typology and indicators. Research Policy 39:79-88. http://dx.doi.org/10.1016/j.respol.2009.09.011

Kinzig, A. P. 2001. Bridging disciplinary divides to address environmental and intellectual challenges. Ecosystems 4:709-715. http://dx.doi.org/10.1007/s10021-001-0039-7

Lattuca, L. R. 2003. Creating interdisciplinarity: grounded definitions from college and university faculty. History of
Intellectual Culture 3(1):1-20. [online] URL: http://www.ucalgary. ca/hic/issues/vol $3 / 5$

Martin-Breen, P., and J. M. Anderies. 2011. Resilience - a literature review. Rockefeller Foundation, New York, New York, USA. [online] URL: http://www.rockefellerfoundation.org/blog/resilienceliterature-review

Mengis, J., D. Nicolini, and J. Swan. 2008. Working together in the space between expertise and ignorance. Proceedings of the Organizational Learning, Knowledge and Capabilities Conference 2008, Copenhagen, Denmark. OLKC, Coventry, UK. [online] URL: http://www2.warwick.ac.uk/fac/soc/wbs/conf/olkc/archive/ olkc3/papers/contribution165.pdf

Millennium Ecosystem Assessment (MEA). 2005. Ecosystems and human well-being: synthesis. Island, Washington, D.C., USA. [online] URL: http://www.millenniumassessment.org/documents/ document.356.aspx.pdf

Mobjörk, M. 2010. Consulting versus participatory transdisciplinarity: a refined classification of transdisciplinary research. Futures 42:866-873. http://dx.doi.org/10.1016/j.futures.2010.03.003

O’Brien, K., B. Hayward, and F. Berkes. 2009. Rethinking social contracts: building resilience in a changing climate. Ecology and Society 14(2): 12. [online] URL: http://www.ecologyandsociety. org/vol14/iss $2 / \operatorname{art} 12 /$

Overbeck, G., A. Hartz, and M. Fleischhauer. 2008. Ein 10punkte-plan "Klimaanpassung." Raumentwicklungsstrategien zum klimawandel im überblick. Informationen zur Raumentwicklung 6/7:363-380.

Ramadier, T. 2004. Transdisciplinarity and its challenges: the case of urban studies. Futures 36:423-439. http://dx.doi.org/10.1016/j. futures.2003.10.009

Smit, B., and J. Wandel. 2006. Adaptation, adaptive capacity and vulnerability. Global Environmental Change 16(3):282-292. http:// dx.doi.org/10.1016/j.gloenvcha.2006.03.008

Stock, P., and R. J. F. Burton. 2011. Defining terms for integrated (multi-inter-trans-disciplinary) sustainability research. Sustainability 3:1090-1113. http://dx.doi.org/10.3390/su3081090

Strunz, S. 2012. Is conceptual vagueness an asset? Arguments from philosophy of science applied to the concept of resilience. Ecological Economics 76:112-118. http://dx.doi.org/10.1016/j. ecolecon.2012.02.012

Walker, B., C. S. Holling, S. R. Carpenter, and A. Kinzig. 2004. Resilience, adaptability and transformability in social-ecological systems. Ecology and Society 9(2): 5. [online] URL: http://www. ecologyandsociety.org/vol9/iss2/art5/

Walker, B. H., L. H. Gunderson, A. Kinzig, C. Folke, S. R. Carpenter, and L. Schultz. 2006. A handful of heuristics and some propositions for understanding resilience in social-ecological systems. Ecology and Society 11(1): 13. [online] URL: http://www. ecologyandsociety.org/vol11/iss1/art13/

Wiechmann, T. 2008. Planung und adaption. Strategieentwicklung in regionen, organisationen und netzwerken. Verlag Dorothea Rohn, Dortmund, Germany. 